\title{
Retinopathy of prematurity treatment: Asian perspectives
}

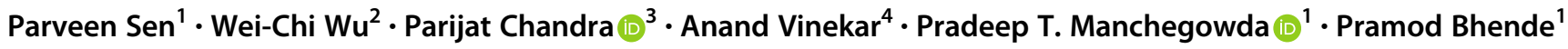

Received: 20 March 2019 / Accepted: 5 July 2019 / Published online: 29 October 2019

(c) The Author(s), under exclusive licence to The Royal College of Ophthalmologists 2019

\begin{abstract}
Retinopathy of prematurity (ROP) is a vasoproliferative disease of developing retinal vessels that affects premature infants and can lead to severe and irreversible visual loss if left untreated. India and some other Asian countries are in the middle of a 'third ROP epidemic'. Blindness due to ROP is largely preventable if appropriate, adequate and accessible screening programmes are available. Screening of the premature babies is the first step in ROP management. With the increase in use of tele-screening techniques, more premature babies have been brought under the screening network both from urban and rural regions. Laser photocoagulation to the avascular retina using indirect ophthalmoscopy delivery system is the gold standard for ROP treatment and is usually done under topical anaesthesia in the Asian region in contrast to the western world. Use of intravitreal anti-vascular endothelial growth factors (VEGF) although controversial in management of ROP has been found to be effective in various Asian studies as well. ROP surgery in India and other middle-income Asian countries is largely performed only in few tertiary eye care centres. Poor visual prognosis, late presentation with advanced retinal detachments, lack of adequate number of trained paediatric retinal surgeons and paediatric anaesthetists also contribute to this problem. This current paper summarizes the Asian experience of ROP management.
\end{abstract}

\section{Introduction}

Retinopathy of prematurity (ROP) is a vasoproliferative disorder of developing retinal vessels that affects premature infants and can lead to severe and irreversible visual impairment or blindness if left untreated. ROP blindness is largely preventable if appropriate, adequate and accessible screening programmes are available. The World Health Organization in 2012 reported that about 15 million babies are born premature annually. Almost one in ten babies is born premature across the world [1]. As survival in these infants has increased, these babies face a lifetime risk of disability including blindness. Among various regions of the world, Southern Asia has the highest number of premature

Pramod Bhende

drpb@snmail.org

1 Shri Bhagwan Mahavir Vitreoretinal Services, Sankara Nethralaya, Chennai, India

2 Chang Gung Memorial Hospital Taoyuan, Taoyuan, Taiwan

3 Dr. Rajendra Prasad Centre for Ophthalmic Sciences, All India Institute of Medical Sciences, New Delhi, India

4 Paediatric Retina Department, Narayana Nethralaya, Bangalore, India infants (13.3\%) making this an important public health issue [2].

With improved neonatal care, in high-income countries, around 1.2 million premature babies have better chances of survival even with lower gestational ages (GA) [2]. Middleincome and developing countries have around 3.8 million preterm babies born each year. But progress in ROPscreening programmes have not kept pace with the progress in neonatal care $[2,3]$. South Asian and Sub-Saharan African countries account for almost two-thirds of the world's preterm babies and over three-quarters of the world's newborn deaths $[2,3]$. Six of the top ten countries with the highest preterm births are in Asia including India, China, Pakistan, Indonesia, Bangladesh and Philippines [3]. This makes ROP one of the major public health problems in the Asian region.

Blencowe et al. in 2010 estimated that, of the 184,700 preterm babies that developed any stage of ROP, 20,000 became blind or severely visually impaired from ROP. Further 12,300 developed mild-to-moderate visual impairment [4]. Sixty-five percent of those visually impaired from ROP were born in the middle-income countries and $6.2 \%$ of all visually impaired infants due to ROP were born at more than 32 weeks gestation [3]. Recent studies suggest that ROP is an increasingly important cause of avoidable blindness in China, Southeast and South Asia [4]. 
This current paper summarizes the Asian experience in ROP management as evident from various studies published from this area. It also highlights how the manifestation and management of ROP in Asian countries is different from that in the developed countries; thus suggesting region specific recommendations to control ROP related blindness.

\section{Problem statement}

Three epidemics have been described in ROP. The first one in the 1940s and 1950s in the western countries was attributed to poor understanding of the disease, and high concentrations of unrestricted oxygen given to the premature babies [5]. Its subsequent curtailment reduced incidence of ROP but increased the incidence of cerebral palsy and death. The second epidemic occurred in developed countries because of increased survival rates of very preterm babies. ROP occurred in these very premature babies despite attempts at titration of oxygen [6].

India and some other Asian countries are in the middle of a 'third ROP epidemic'. The hallmark of this epidemic is a variable spectrum of the disease. In tertiary care institutes which have a relatively high level of care, only the extremely premature are at risk of ROP (akin to the second epidemic of the west). However, in rural and semi-urban regions, even heavier and more mature premature infants are seen to suffer from the disease [4].

In 2010, of the estimated preterm births, number of eyes with ROP related severe visual impairment was estimated globally [4]. The problem statement in the Asian region can be summarized in Table 1, which is adapted from the study by Blencowe et al. [4]. This compares the geographic regions of Asia with high-income countries. Larger number of premature infants born, greater incidence of treatment requiring disease and fewer babies undergoing timely treatment leads to a large burden of infants becoming blind or severely visually impaired in Asian countries as compared with other regions of the world [4].

Dutta et al. [7] have suggested possible reasons for the increased ROP burden in India. These include, high rate of prematurity (in India over $13 \%$ babies are born premature); improved survival of preterm babies (survival rates of infants between 28 and 32 weeks of GA have improved from 75 to $93 \%$ ); unrestricted use of oxygen; lack of adequate sensitization of care providers of these preterm babies and lack of uniform ROP-screening protocols [7]. This has resulted in 'heavier' and 'more mature' infants developing severe blinding stage 5 ROP compared to their western counterparts [8].

\section{ROP-screening guidelines}

Screening is the first step in management of ROP. This requires training, skill and appropriate equipment. Screening guidelines that are acceptable nationally can serve as a strong backbone to homogenize screening programmes in any country. Western guidelines which focus on infants born $<1500 \mathrm{~g}$ or born at a GA of $<30$ weeks have been shown to be inadequate to cover the 'at-risk' infants in the middle-income countries [8, 9]. Many countries have therefore adopted different ROP-screening criteria to cater to their regional ROP profile.

In India, in 2010 the National Neonatology Forum in collaboration with the ophthalmologists released guidelines that recommended screening of premature infants of gestation $<34$ weeks and birth weight $(\mathrm{BW})<1750 \mathrm{~g}$ and in those babies born with a BW of 1750-2000 g, if there were additional risk factors [10]. In 2015 the Ministry of Health, Government of India released a universal vision screening and ROP guidelines integrating ROP into the universal screening programme, the 'Rashtriya Bal Swasthya Karyakram (RBSK)' and the National Program for Control of Blindness (NPCB) which was followed by an Operational

Table 1 Distribution of ROP demographics in the Asian regions

\begin{tabular}{|c|c|c|c|c|c|}
\hline & Central Asia & $\begin{array}{l}\text { East and } \\
\text { Southeast Asia }\end{array}$ & South Asia & $\begin{array}{l}\text { High-income } \\
\text { countries }\end{array}$ & Total \\
\hline $\begin{array}{l}\text { Live births and } \% \text { of } \\
\text { worldwide total }\end{array}$ & 5.4 million $(4 \%)$ & 29 million $(22 \%)$ & 37.1 million $(28 \%)$ & 11.7 million $(9 \%)$ & 135 million $(100 \%)$ \\
\hline Preterm births & $413,000(3 \%)$ & $2,808,000(19 \%)$ & $4,954,000(33 \%)$ & $1,064,000(7 \%)$ & $14,900,000(100 \%)$ \\
\hline Any stage ROP & 17,200 & 64,000 & 16,800 & 32,700 & 184,700 \\
\hline Treatment requiring $\mathrm{ROP}$ & 5200 & 19,900 & 5300 & 6300 & 53,800 \\
\hline Receiving treatment & 1900 & 7800 & 1100 & 5500 & 22,700 \\
\hline $\begin{array}{l}\text { Survivors with blindness/severe } \\
\text { vision impairment }\end{array}$ & 2000 & 7500 & 2200 & 1700 & 20,000 \\
\hline $\begin{array}{l}\text { Survivors with mild/moderate } \\
\text { vision impairment }\end{array}$ & 1100 & 4400 & 900 & 2300 & 12,300 \\
\hline
\end{tabular}

Modified from Blencowe et al. [4] 
Guidelines for ROP (2017) by the National Task Force of ROP, Government of India. These guidelines suggest that preterm babies $\leq 2000 \mathrm{~g} \mathrm{BW}$ and $\leq 34$ weeks GA should be screened for ROP. Bigger babies born at 34-36 weeks GA can also be screened if they have high-risk factors for developing ROP. The guidelines emphasize that all these babies should have first screening within the first 4 weeks of life. Babies born with $\mathrm{BW} \leq 1200 \mathrm{~g}$ and $\mathrm{GA} \leq 28$ weeks could be screened at 2-3 weeks of life [11].

Similar to India, in China the ROP-screening guidelines recommended in 2004 were $\mathrm{GA} \leq 34$ weeks and/or $\mathrm{BW} \leq$ $2000 \mathrm{~g}$ [12]. Some Chinese studies have suggested to reduce the criteria to $\mathrm{GA} \leq 33$ weeks and $\mathrm{BW} \leq 1750 \mathrm{~g}$ as this may still detect all treatable ROP [13]. In Turkey, screening of infants with a GA $\leq 34$ weeks or a BW $<1700$ $\mathrm{g}$ has been suggested to be appropriate across a prospective, multicentre study in 69 neonatal intensive care units [14]. A report from Thailand suggested screening guidelines for babies with GA $<33$ weeks and/or $\mathrm{BW}<1500 \mathrm{~g}$. Using this screening criteria, they achieved a sensitivity of $100 \%$ and specificity of $18.3 \%$, while using the American $(\mathrm{BW}<$ $1500 \mathrm{~g}$ and $\mathrm{GA}<28$ weeks) and British guidelines, the sensitivity was $93 \%$ and specificity was $35-40 \%$ [15]. However, in a prospective study from Korea, though the screening criteria were similar to that advised by the international committee (BW $<1500 \mathrm{~g}$ and/or $\mathrm{GA}<30$ weeks), the incidence of ROP in infants with $\mathrm{GA} \geq 31$ weeks was found to be $8.4 \%$, thus, emphasizing the importance of screening even older infants when indicated [16]. Higher income group countries within Asia like Taiwan [17], Singapore [18] and Japan [19] follow screening guidelines similar to the UK/US. ROP screening guidelines followed in some Asian countries are summarized in Table 2.

Meanwhile tele-screening models continue to develop across the region with wider availability of wide-field digital imaging cameras (Fig. 1). The ability of experts based in tertiary hospitals or reading centres to opine regarding treatment and follow-up based on images captured by trained technicians in mobile-screening teams has enabled provision of a large coverage of ROP-screening care in the community. The 'K.I.D.R.O.P' model [20] is an example of such a successful tele-screening programme in Karnataka (India) under private-public partnership which provides ROP screening in low-resource settings, remote centres and regions with few ROP specialists. An impact assessment of the image based tele-ROP programme in India showed that in the ten high-risk ROP states with a population of roughly 680 million, over 35,000 infants were detected with ROP and over 1200-needed treatment

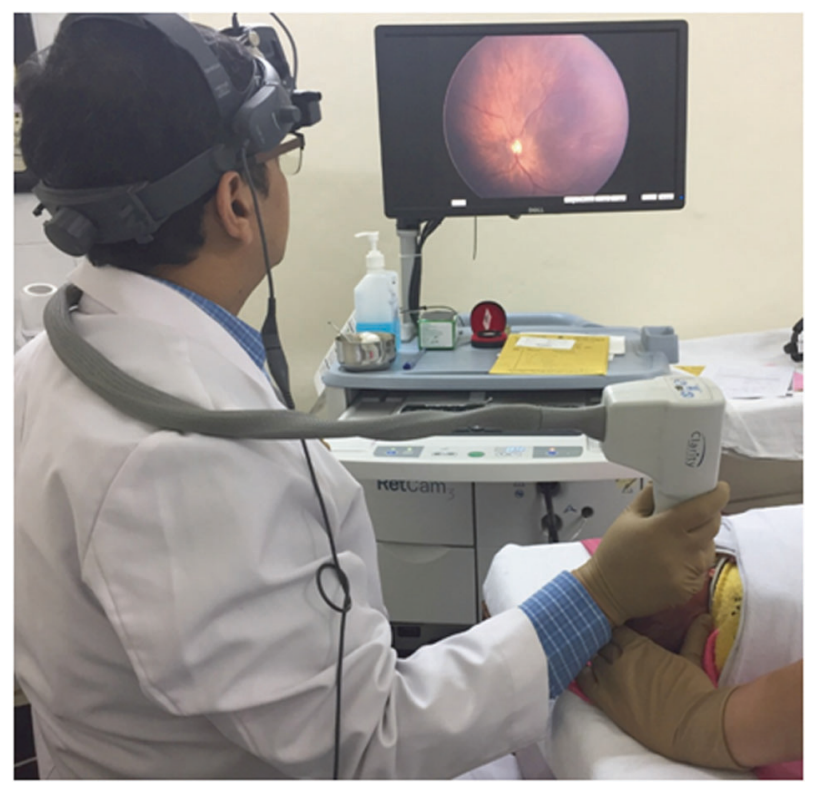

Fig. 1 Wide-field digital ROP screening by Retcam imaging

Table 2 ROP-screening guidelines in the Asian region compared with US/UK guidelines

\begin{tabular}{llllll}
\hline Study group & Country & Year & Screening criteria & & $\begin{array}{l}\text { Timing of first screening } \\
\text { (Age in weeks after birth) }\end{array}$ \\
\cline { 5 - 6 } & & & Birth weight (grams) & Gestational age (weeks) & 4 \\
Fierson et al. [9] & USA & 2013 & 1500 & 30 & $4-5$ \\
Wilkinson et al. [63] & UK & 2009 & 1500 & 32 & $4<27$ weeks) \\
(GA & & & & $2-3$ weeks \\
RBSK and NPCB [11] & India & 2017 & 2000 & $34-36$ (risk factors) & (GA $<28$ weeks/BW < 1200 g) \\
& & & & & $4-6$ \\
Chinese Expert group [12] & China & 2004 & 2000 & 34 & 4 \\
Bas et al. [14] & Turkey & 2018 & 1700 & 34 & $4-6$ \\
Trinavarat et al. [15] & Thailand & 2004 & 1500 & 33 & 6 \\
Shah et al. [18] & Singapore & 2005 & 1500 & 32 & $4-6$ \\
Chen et al. [17] & Taiwan & 2015 & 1500 & 32 & $4-6$ \\
Al Amro SA et al. [64] & Saudi Arabia & 2018 & 1500 & $32-36$ (risk factors) & \\
\hline
\end{tabular}


annually. The fiscal quantum of burden in 'blind-personyears' that could possibly be saved using this model is 108 million USD [21].

\section{ROP treatments}

\section{Laser therapy}

The gold standard for ROP treatment in the Asian region is laser photocoagulation delivered through laser indirect ophthalmoscopy (LIO), although there has been an increasing trend to use anti-vascular endothelial growth factor (anti-VEGF) agents more recently. There is again a gross lack of trained specialists to perform laser. The Indian ROP (iROP) society reported that less than 100 specialists were comfortable performing laser [22]. This gap between those requiring treatment and those receiving therapy is reflected in the increasing number of blind and visually impaired infants (Table 1).

In the UK, over 50\% ophthalmologists treating ROP with laser photocoagulation used general anaesthesia and $37 \%$ use intravenous sedation [23]. In contrast, in the Asian region including India, China, Iran and Hong Kong, treatment is most commonly performed under topical anaesthesia (Table 3). Figure $2 \mathrm{a}$, b shows indirect ophthalmoscopic examination and LIO by $532 \mathrm{~nm}$ green laser under topical anaesthesia, respectively. Sedation [24, 25], remifentanil analgesia [26] and oral pellets of sucrose or dextrose are other additional modifications used by various ophthalmologists for pain relief during laser treatment. In Japan, a study comparing topical vs general anaesthesia, showed that the former had fewer systemic complications [27]. Though inhalation anaesthesia did not affect the vital signs at all during the laser, it has its own problems in premature infants and adverse effects on neurodevelopment. Also, it increases the dependence on anaesthetists and operating room facilities which may not be widely available especially in the developing Asian countries.
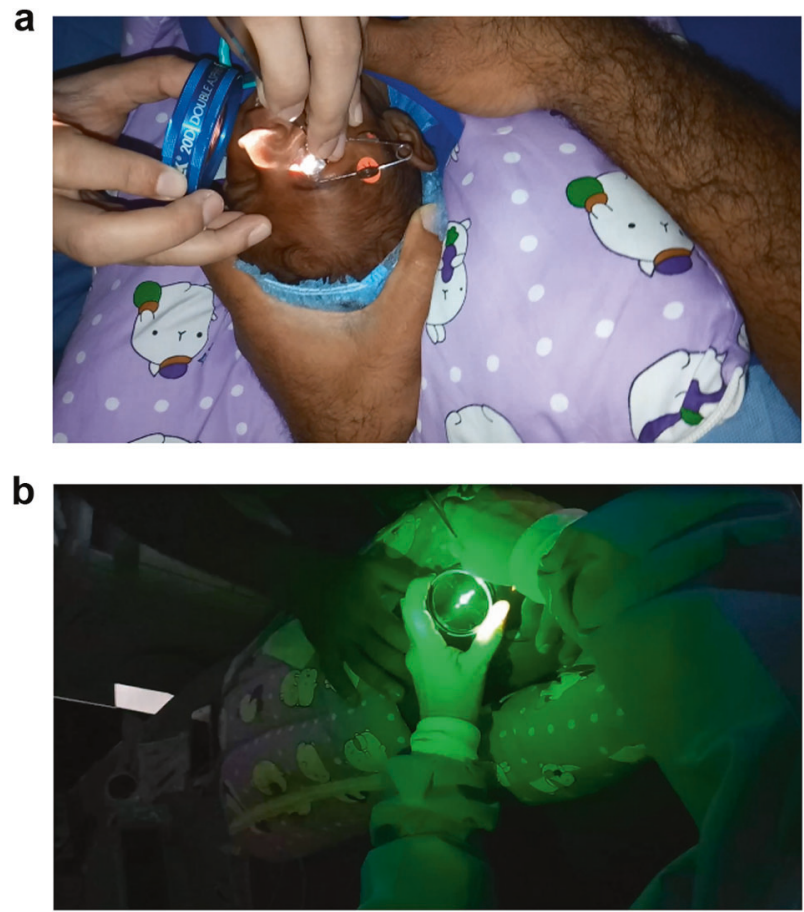

Fig. 2 a Indirect ophthalmoscopic examination with scleral indentation for ROP screening under topical anaesthesia. b Photoablation by laser indirect ophthalmoscopy using $532 \mathrm{~nm}$ green laser also under topical anaesthesia

Table 3 Laser treatment outcomes for ROP from Asia

\begin{tabular}{|c|c|c|c|c|c|c|c|c|}
\hline Sl no. & Author & Country & Year & Study type & $\begin{array}{l}\text { No. } \\
\text { of eyes }\end{array}$ & Anaesthesia & $\begin{array}{l}\text { Favourable structural } \\
\text { outcomes }(\%)\end{array}$ & Comments \\
\hline 1 & Sanghi et al. [65] & India & 2010 & Retrospective & 260 & TA & 97 & $\begin{array}{l}\text { Diode and green laser are similar in } \\
\text { efficacy and safety }\end{array}$ \\
\hline 2. & Axer-Siegel et al. [24] & Israel & 2008 & Retrospective & 194 & Sedation & 92.3 & Diode laser is safe and effective \\
\hline 3. & Jalali et al. [66] & India & 2011 & Prospective & 227 & TA & 87.5 & Laser in Zone 1 ROP eyes \\
\hline 4 & Uparkar et al. [67] & India & 2010 & prospective & 100 & TA & $94-98$ & $\begin{array}{l}\text { Laser to the ridge and posterior also safe } \\
\text { and effective }\end{array}$ \\
\hline 5 & Parvaresh et al. [68] & Iran & 2013 & Prospective & 139 & TA & 100 & $\begin{array}{l}\text { Transscleral laser ablation was used. } \\
\text { Severe chemosis, conjunctival lacerations } \\
\text { in } 8.6 \% \text { eyes. Supplemental transpupillary } \\
\text { laser for zone } 1 \text { eyes }\end{array}$ \\
\hline 6 & Jiang et al. [25] & China & 2014 & Retrospective & 97 infants & $\begin{array}{l}\text { TA (31) Sedation } \\
\text { (47) GA (19) }\end{array}$ & 96.9 & $\begin{array}{l}\text { Laser under topical required more duration } \\
\text { of treatment and was associated with more } \\
\text { cardiorespiratory instability during and } \\
\text { after treatment. }\end{array}$ \\
\hline 7 & Sato et al. [27] & Japan & 2015 & Prospective & 49 & $\begin{array}{l}\text { Local (L)-15 } \\
\text { pentazocine (P)-11 I. } \\
\text { V Fentanyl (F)-11 } \\
\text { Inhalation (I)-12 }\end{array}$ & - & $\begin{array}{l}\text { L-No significant adverse side effects } \\
\text { except desaturation during procedure. In } \\
\text { group I more chances of hypothermia, } \\
\text { apnoea, oliguria }\end{array}$ \\
\hline 8 & Vinekar et al. [69] & India & 2015 & Prospective & 29 & TA & & $\begin{array}{l}\text { Compared single vs two-staged laser for } \\
\text { APROP. Latter has fewer complications }\end{array}$ \\
\hline
\end{tabular}

$T A$ topical anaesthesia, $G A$ general anaesthesia, $I . V$ intravenous 
Laser is performed inside the neonatal unit, operating room or a facility where the infant can be monitored by a paediatrician or an anaesthetist. Diode laser has been widely replaced in many centres by the $532 \mathrm{~nm}$ green laser. The latter was reported to have distinct advantages such as ease of use, lower tissue penetration, less pain, less cost and better portability. Furthermore, the green laser can be utilized for diabetic retinopathy treatment as well adding a cost utility benefit in middle-income countries where resources are limited.

Dogra et al. showed that infants too sick to be transported outside the incubator can be treated successfully through the double-walled sloping incubator with either diode or green laser [28]. Posterior to the ridge laser was proposed by Ells et al. [29] when the fibrovascular proliferation is raised in the vitreous cavity (stage 3 ). This approach has apparently resulted in better regression of ROP, less traction and a more favourable outcome [29].

Highly favourable outcome following laser has been reported in many Asian studies. Over $96-100 \%$ of success for type 1 ROP eyes treated with laser has been reported [30]. Sanghi et al. proposed that darker retinal pigment, dense and thorough laser, close follow-up and early prompt treatment could be reasons for a higher success rate compared with western infants. Although aggressive posterior ROP (APROP) outcome following laser treatment is relatively poor (between 82.5 and $100 \%$ ), few studies from India have reported good structural outcomes in these eyes [31]. GA $<29.5$ weeks and presence of pre-retinal haemorrhage were found to be individual risk factors for poor outcome in eyes with APROP [31]. APROP has been reported in heavier babies in India presumably due to prolonged and uncontrolled exposure to high concentration of oxygen and other comorbid conditions [32]. A comparison of laser practices and outcomes in few Asian studies is summarized in Table 3.

\section{Anti-VEGF therapy}

After the BEAT-ROP study [33], anti-VEGF therapy has gained popularity for the treatment of ROP. In India and other Asian countries which lack adequate ROP specialists who can perform laser, this new modality has provided another alternative. However, the indications, the appropriate dosages, follow-up strategy, associated comorbidities and systemic safety remain unmet challenges. Different Anti-VEGF agents used for ROP include Bevacizumab (Avastin; Genentech Inc., South San Francisco, CA, USA), Ranibizumab (Lucentis; Genentech Inc., South San Francisco, CA, USA) and Aflibercept (Eylea; Regeneron Pharmaceuticals, Tarrytown, NY, USA). Bevacizumab and Ranibizumab are the more commonly used agents for treating ROP. There is no definite agreement regarding optimal dose of these anti-VEGF medications in ROP. Most previous studies have used $0.625 \mathrm{mg} / 0.025 \mathrm{ml}$ for Bevacizumab and $0.25 \mathrm{mg} / 0.025 \mathrm{ml}$ for Ranibizumab, or half of the adult doses, per eye when injected in these newborn eyes. Recent studies have found that even low-dose Bevacizumab to be equally effective with theoretically reduced risk of side effects [34].

Advantages of anti-VEGFs over laser include easier and faster administration, less structural damage, reduced refractive error, possible treatment in special scenarios like hazy media, corneal opacification, non-dilating pupil and ischaemia involving the posterior pole.

The potential disadvantages include unknown variables about the accurate dose required, the frequency and duration of follow-up, detection and management of recurrences, persistent peripheral avascularity, long-term effect on visual acuity and fields, systemic adverse effects particularly involving neurodevelopmental delay. Besides, medico-legal considerations are very important in countries like India. After the ban and subsequent reinstating of anti-VEGF agents for the use of adult retinal diseases by the Government of India, there is still no legal sanctity for the use of these agents in infants potentially exposing the treating specialist to liability. More importantly, rural patients who may not be able to follow-up indefinitely after therapy are at risk of late, undetected and untreated recurrences.

A report from Pakistan (15 eyes), in advanced stage 3 or 4 ROP, combination therapy of laser and anti-VEGF showed reduction in neovascular activity signs such as reduced tortuosity and vessel dilatation without requiring additional treatment. No systemic or ocular serious adverse events were observed [35]. Xu et al. from China investigated the use of Ranibizumab for APROP (37 eyes) associated with vitreous haemorrhage and found such approach improved fundus visibility to apply lasers at mean time of $4.8 \pm 2.9$ weeks and observed $92 \%$ eye had favourable anatomical outcome [36]. Shah et al. used Bevacizumab to successfully treat anterior segment ischemic Syndrome, a rare complication following laser ablation therapy in an eye with APROP [37]. In a multicentre study in Taiwan, $\mathrm{Wu}$ et al. reported vitreous or preretinal haemorrhage in $8 \%$ of eyes and transient venous sheathing in $4 \%$ of eyes as complications of intravitreal Bevacizumab (IVB) injection; however, vitreous or preretinal haemorrhage later resolved in all eyes, and sheathed vessels reperfused at subsequent follow-ups [38]. Serious adverse events of retinal break/s and bilateral vascular attenuation with subretinal perivascular exudates and optic atrophy were also reported after IVB in a series from India [39]. Another concern from treatment induced complication termed 'ROP crunch', can occur, if anti-VEGF injection was performed in eyes with preexisting significant retinal traction [40]. 
Table 4 Anti-VEGF therapy outcomes for ROP from Asia

\begin{tabular}{|c|c|c|c|c|c|c|c|c|c|}
\hline Sl no. & Author & Country & Year & Study type & Eyes & $\begin{array}{l}\text { Intravit } \\
\text { therapy }\end{array}$ & Dose (mg) & Outcome & Complications \\
\hline 1 & WU et al. [45] & Taiwan & 2013 & $\begin{array}{l}\text { Retrospective } \\
\text { (monotherapy) }\end{array}$ & 162 & IVB & 0.625 & $\begin{array}{l}\text { New vessel regression- } 88 \% \\
\text { worsening- } 2 \%\end{array}$ & $\begin{array}{l}\mathrm{VH} \text {, cataract. } \\
\text { Systemic-none }\end{array}$ \\
\hline 2 & Jalali et al. [39] & India & 2013 & $\begin{array}{l}\text { Prospective } \\
\text { (rescue therapy) }\end{array}$ & 24 & IVB & 0.625 & $\begin{array}{l}\text { New vessel regression- } \\
100 \%\end{array}$ & $\begin{array}{l}\text { Retinal break, } \\
\text { perivascular exudation, } \\
\text { optic atrophy, hepatic } \\
\text { dysfunction }\end{array}$ \\
\hline 3 & Kusaka et al. [70] & japan & 2008 & $\begin{array}{l}\text { Retrospective } \\
\text { (rescue therapy in } \\
\text { progressive ROP) }\end{array}$ & 23 & IVB & 0.5 & $\begin{array}{l}\text { Reduced vascularity, } \\
\text { decreased intra and post op. } \\
\text { bleeding, reproliferation }\end{array}$ & Persistent high IOP \\
\hline 4 & Yetik et al. [71] & Turkey & 2015 & $\begin{array}{l}\text { Prospective } \\
\text { (monotherapy) }\end{array}$ & 238 & IVB & 0.625 & $\begin{array}{l}\text { Success rate by } 1 \text { st inj- } \\
95.4 \% \text { 2nd inj- } 98.2 \% \text { 3rd } \\
\text { inj-100\% } \\
\text { Worsening- } 0 \%\end{array}$ & $\begin{array}{l}\text { Subconjunctival } \\
\text { haemorrhage }\end{array}$ \\
\hline 5 & Huang et al. [72] & China & 2017 & $\begin{array}{l}\text { Retrospective } \\
\text { (monotherapy) }\end{array}$ & 283 & IVR & 0.25 & $\begin{array}{l}\text { Complete regression with } \\
\text { no reactivation- } 45.8 \% \\
\text { Reactivation- } 44.4 \%\end{array}$ & VH, cataract \\
\hline
\end{tabular}

IVB intravitreal Bevacizumab, IVR intravitreal ranibizumab, $V H$ vitreous haemorrhage, Inj. injection

Systemic complications after anti-VEGF therapy are due to the fact that VEGF levels are depressed for 2-3 months after intravitreal anti-VEGF injection in patients with type 1 ROP probably due to the leakage of the drug into the systemic circulation [41, 42]. A retrospective observational study revealed that preterm infants treated with Bevacizumab had higher odds (as compared with laser) of severe neurodevelopmental disabilities [43]. However $\mathrm{Wu}$ et al., did not find worse neurodevelopmental outcomes in infants who received only Bevacizumab, as compared with those treated with laser photocoagulation [44, 45]. The results of anti-VEGF therapy reports from the Asian region are summarized in Table 4.

\section{ROP surgery}

ROP surgery in India and other middle-income countries are performed only at a few tertiary care centres. Poor visual prognosis, late presentation of advanced retinal detachments (RD), lack of trained paediatric retinal surgeons, lack of paediatric anaesthetists and neonatal support after surgery, poor follow-up after surgery, and lack of vision rehabilitation and supportive therapy, all contribute to the problem.

Scleral buckling involving the placement of 240 band at the height of the tractional retinal detachment (TRD) by making scleral tunnels in all quadrants, is done only in a select group of Stage 4 eyes with only peripheral traction. Segmental scleral buckles have also been used by Chuang et al. [46] for TRD limited to the temporal quadrants, with macular attachment rates of $79 \%$ in a small series of 15 eyes.

Lens sparing vitrectomy (LSV) is the most commonly performed surgery for stage 4 ROP. Nishina et al., demonstrated using fluorescein angiography, before and after surgery that removal of proliferation tissue promptly reduced the vascular activity, limiting the progress of RD in APROP [47]. With advent of microincisional vitrectomy surgeries (MIVS), ROP surgeries now are becoming more popular. Also, intraoperative and postoperative complications appear to be much lesser with MIVS [48].

Gadkari et al. noted that eyes that have undergone prior laser have less chances of iatrogenic retinal break during surgery as compared with treatment naive eyes [49]. Bhende et al., reported an anatomical success of $96 \%$ in stage $4 \mathrm{~A}$ and $70 \%$ in stage $4 \mathrm{~B}$ following LSV at final visit [50]. Use of pre-operative Bevacizumab has been advocated by $\mathrm{Xu}$ et al. from China who found that eyes undergoing LSV with pre-operative Bevacizumab had significantly shorter surgical time (74 vs $101 \mathrm{~min}$ ), better attachment rate (100 vs 70\%), and better visual outcome (88 vs 30\%) [51]. Recently, early VR surgery has been propagated in APROP eyes to prevent development of RD [52]. A combination of all possible modalities may be necessary in APROP. Figure $3 \mathrm{a}, \mathrm{b}$ shows regression of stage $4 \mathrm{~A}$ zone 1 ROP following 25 gauge LSV.

Multiple case series in India and other Asian countries have reported anatomical success ranging from 75 to $100 \%$ in stage $4 \mathrm{~A}$ and between 62 and $100 \%$ in stage 4B ROP following LSV. The outcomes are summarized in Table 5.

Stage 5 ROP has the worst prognosis. Once retrolental fibroplasia has formed, lensectomy is done along with vitrectomy. Gopal et al. have reported almost $81 \%$ incidence of close-close configuration of RD in his series undergoing surgery for stage 5 ROP which is associated with poorer prognosis [53]. Choi et al. reported 
postoperative intraocular haemorrhage using 20 gauge system in nearly $43 \%$ of cases [54], while Gonzales et al. reported postoperative vitreous haemorrhage in $13.3 \%$ of cases after 25 gauge MIVS for stage 4 and 5 ROP [48]. Gopal et al. had anatomical success with the attachment of

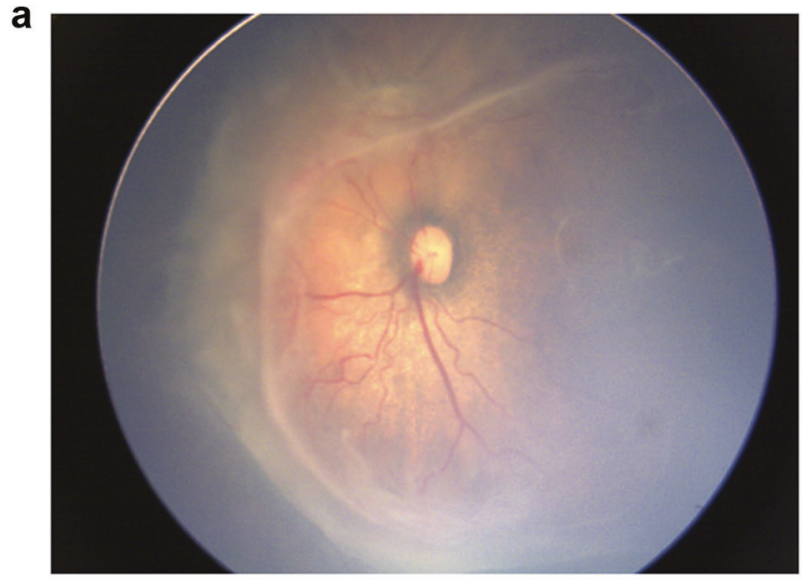

b

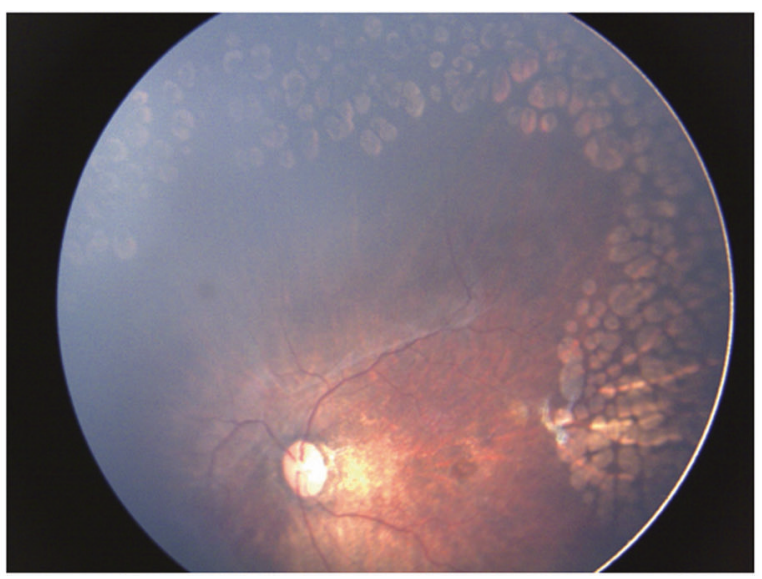

Fig. 3 a Left eye with circumferential Stage 4A ROP in Zone 1. b Left eye 4 weeks after $25 \mathrm{G}$ LSV showing regressed ROP posterior pole in $22.5 \%$ of cases with lens sacrificing closed globe vitrectomy for stage 5 ROP [53]. Recurrence of RD has been observed in $22 \%$ of cases in Stage 5 as compared with $5 \%$ in stage 4 , highlighting the importance of prolonged follow-up of these eyes [55]. Plasmin assisted vitrectomy with encouraging results, for primary as well as recurrent $\mathrm{RD}$ in regressed $\mathrm{ROP}$ has been reported by $\mathrm{Wu}$ et al. [56]. The most important aspect of treatment for stage 5 ROP is the education of parents or guardians regarding the limited visual outcomes that may be seen in a small proportion of eyes undergoing surgery and the need for prolonged follow-up.

Long-term follow-up is necessary not only in postsurgery eyes but also in all premature babies because of the high incidence of refractive errors. The Asian studies are summarized in Table 6. Functional outcomes and refractive errors noted after multiple treatment modalities are summarized in Table 7.

Because of the heterogeneity in the presentation of disease in babies with similar neonatal risk factors, genetic predisposition has also been studied by the Asian researchers [57, 58].

\section{Medico-Legal aspects of ROP}

In India in 2015, a landmark judgement by the Supreme Court awarded a USD 300,000 compensation to a child who was not referred for timely ROP screening. Subsequent cases highlighted the vulnerability of the ROP problems for the infants and the caregivers. Stricter enforcement of the national screening guidelines, with increase in trained resources for screening and treatment along with strengthening preventive measures is the need of the hour. This will require stronger public and private partnerships and the use of innovative technologies to combat the ROP scourge.

Table 5 Lens sparing vitrectomy outcomes for ROP from Asia

\begin{tabular}{|c|c|c|c|c|c|c|c|}
\hline Sl no. & Author & Country & Year & Type & Eyes & $\begin{array}{l}\text { Anatomical } \\
\text { outcome }(\%)\end{array}$ & $\begin{array}{l}\text { Favourable visual } \\
\text { outcome }(\%)\end{array}$ \\
\hline 1 & Choi et al. [54] & Korea & 1999-2007 & Retrospective & $\begin{array}{l}4 \mathrm{~B}-13 \\
5-8\end{array}$ & $\begin{array}{l}4 \mathrm{~B}-62 \\
5-13\end{array}$ & - \\
\hline 2 & Bhende et al. [50] & India & 2000-2006 & Retrospective & $\begin{array}{l}4 \mathrm{~A}-29 \\
4 \mathrm{~B}-10\end{array}$ & $\begin{array}{r}\text { 4A-96, } \\
4 \mathrm{~B}-70\end{array}$ & $\begin{array}{l}4 \mathrm{~A}-86 \\
4 \mathrm{~B}-60\end{array}$ \\
\hline 3 & Yu et al. [73] & Korea & 1999-2003 & Retrospective & $\begin{array}{l}4 \mathrm{~A}-4, \\
4 \mathrm{~B}-9, \\
5-4\end{array}$ & $\begin{array}{l}4 \mathrm{~A}-75 \\
4 \mathrm{~B}-66.7, \\
5-25\end{array}$ & - \\
\hline 4 & Azuma et al. [52] & Japan & 2004-2005 & Retrospective & 6 (APROP) & 100 & NA \\
\hline 5 & Wu et al. [74] & Taiwan & 2007-2010 & Retrospective & $4 \mathrm{~A}-15,4 \mathrm{~B}-11$ & 88 & NA \\
\hline 6 & Gadkari et al. [75] & India & 2015 & Prospective & $\begin{array}{l}4 \mathrm{~B}-20 \\
5-11\end{array}$ & $\begin{array}{l}4 \mathrm{~B}-90, \\
5-45.5\end{array}$ & NA \\
\hline 7 & Shah et al. [76] & India & 2018 & Retrospective & $\begin{array}{l}4 \mathrm{~A}-7 \\
4 \mathrm{~B}-2\end{array}$ & 100 & - \\
\hline
\end{tabular}

NA not available 
Table 6 Stage 5 surgery outcomes for ROP

\begin{tabular}{lllllll}
\hline S1 no. & Author & Country & Year of study & Type & Eyes & $\begin{array}{l}\text { Anatomical } \\
\text { outcome (\%) }\end{array}$ \\
\hline 1 & Choi et al. [54] & Korea & $1999-2007$ & Retrospective & 8 & 13 \\
2 & Gadkari et al. [75] & India & 2009 & Prospective & 11 & 45.5 \\
3 & Shah et al. [77] & India & $2001-2006$ & Retrospective & 14 & 14.3 \\
4 & Karacorlu et al. [78] & Turkey & $1996-2010$ & Retrospective & 31 & 42 \\
5 & Gopal et al. [53] & India & $1992-1998$ & Retrospective & 96 & 22.9 \\
6 & Kono et al. [79] & Japan & $1989-1991$ & Retrospective & 51 & 47 \\
7 & Cusick et al. [80] & USA & $1977-2001$ & Retrospective & 608 & 33 \\
\hline
\end{tabular}

Table 7 Functional outcomes of ROP treatment

\begin{tabular}{|c|c|c|c|c|c|c|c|c|c|c|c|}
\hline Sl no. & Author & Country & $\begin{array}{l}\text { Year of } \\
\text { publication }\end{array}$ & $\begin{array}{l}\text { Type } \\
\text { of study }\end{array}$ & Intervention & Eyes & ROP stage & $\begin{array}{l}\text { Mean SE } \\
\text { (Dioptres) }\end{array}$ & Myopia (\%) & $\begin{array}{l}\text { High } \\
\text { myopia }(\%)\end{array}$ & $\begin{array}{l}\text { Follow-up } \\
\text { (years) }\end{array}$ \\
\hline 1 & Katoch et al. [30] & India & 2011 & Retrospective & Laser & 69 & Type 1 & +0.75 & 26.1 & 1.4 & 1 \\
\hline 2 & Axer-Siegel et al. [81] & Israel & 2008 & Retrospective & Laser & 134 & $\begin{array}{l}\text { Type } 1 \text { or } \\
\text { threshold }\end{array}$ & 1.5 & 55.2 & 23.9 & 2.9 \\
\hline \multirow[t]{2}{*}{3} & \multirow[t]{2}{*}{ Agarkar et al. [82] } & \multirow[t]{2}{*}{ India } & \multirow[t]{2}{*}{2017} & \multirow[t]{2}{*}{ Retrospective } & Laser + LSV & 14 & Stage 4A, 4B & -7.4 & NA & NA & \multirow[t]{2}{*}{2} \\
\hline & & & & & Laser & 14 & Type 1 & -6.4 & NA & NA & \\
\hline \multirow[t]{3}{*}{4} & \multirow[t]{3}{*}{ Chen et al. [83] } & \multirow[t]{3}{*}{ Taiwan } & \multirow[t]{3}{*}{2014} & \multirow[t]{3}{*}{ Retrospective } & IVB & 40 & $\begin{array}{l}5 \text {-stage 2, 52- } \\
\text { stage } 3\end{array}$ & -0.98 & 47.5 & 10 & \multirow[t]{3}{*}{2} \\
\hline & & & & & IVB + Laser & 17 & & -2.4 & 82.4 & 29.4 & \\
\hline & & & & & IVB + LSV & 7 & Stage $4 \mathrm{~A}$ & -14.4 & 100 & 100 & \\
\hline 5 & Yang et al. [84] & Taiwan & 2010 & Retrospective & Laser & 60 & Threshold & -3.87 & 60.3 & 16.7 & 7.8 \\
\hline 6 & Shah PK et al. [85] & India & 2014 & Retrospective & Laser & 48 & APROP & -6.14 & 4.1 & NA & 6.9 \\
\hline
\end{tabular}

$S E$ spherical equivalent, High myopia More than 5D of myopia, $L S V$ lens sparing vitrectomy, IVB intravitreal Bevacizumab, NA not available, Cryo cryotherapy

The United Nation Development Programme report on the Indian tele-imaging programme and the National Health and Medical Research Council (Australia) report based on the Center for Disease Control guidelines on the KIDROP tele-ROP programme, both strongly suggest that wide-field imaging is likely to become the new gold standard in ROP screening [59], which may guard the medico-legal interest of the patients and the caregivers in countries like India and others with similar ROP demographics.

\section{Advances in technology}

Innovations in ROP management from India have been recently reported and include: (1) affordable imaging technologies-an indigenous ROP camera was developed in a collaboration between the Government, Industry and clinical partners (3Nethra Neo, Forus Health, India) [60]. This portable camera is lighter, uses a uni-body liquid lens system and is wide-field, using a light-emitting diode illumination and providing $120^{\circ}$ of view [60]. (2) Online training and e-certification platforms such as the WISE-ROP model that allows training of remote non-physicians to capture and report images [61]. (3) Software and artificial intelligence that may help diagnose, predict and prognosticate the disease. (4) Novel service delivery models-a paediatrician led model wherein nurses screen for ROP using ROP cameras is being piloted in South India based on suggestions by Gilbert et al. [62].

\section{Conclusion}

A significant part of Asia is suffering from the third epidemic of ROP. Corrective measures need to be initiated right from the time of birth of a premature child and these include (1) increase in the availability of compressed air supply, air-oxygen blenders, trained doctors and nurses, (2) disseminate knowledge about oxygen saturation targets, (3) improve ROP screening and treatment, (4) maintain a nation-wide database of all babies who are treated and those diagnosed with ROP blindness, (5) introduce newer technology for the better and early diagnosis of ROP, (6) educating parents regarding ROP and (7) conduct research to understand the epidemiology of prematurity and translational research to minimize the known risk factors of ROP. Only combined efforts of paediatricians, neonatologists, obstetricians, ophthalmologists, nurses and parents with support from their Governments can help achieve this.

\section{Compliance with ethical standards}

Conflict of interest The authors declare no conflict of interest. 
Publisher's note Springer Nature remains neutral with regard to jurisdictional claims in published maps and institutional affiliations.

\section{References}

1. World Health Organization. Born too soon: the global action report on preterm birth. World Health Organization. http://www. who.int/pmnch/media/news/2012/201204_borntoosoon-report.pdf. (News release dated 2 May 2012).

2. Blencowe H, Cousens S, Chou D, Oestergaard M, Say L, Moller $\mathrm{AB}$, et al. Born too soon: the global epidemiology of 15 million preterm births. Reprod Health. 2013;10:S2.

3. Lawn JE, Davidge R, Paul VK, von Xylander S, de Graft Johnson J, Costello A, et al. Born too soon: care for the preterm baby. Reprod Health. 2013;10:S1-5.

4. Blencowe H, Cousens S, Oestergaard MZ, Chou D, Moller AB, Narwal R, et al. National, regional, and worldwide estimates of preterm birth rates in the year 2010 with time trends since 1990 for selected countries: a systematic analysis and implications. Lancet. 2012;379:2162-72.

5. Cross CW. Cost of preventing retrolental fibroplasia. Lancet. 1973;2:954-6.

6. Lucey JF, Dangman B. A reexamination of the role of oxygen in retrolental fibroplasia. Pediatrics. 1984;73:82-96.

7. Dutta S, Raghuveer T, Vinekar A, Dogra MR. Can we stop the current epidemic of blindness from Retinopathy of Prematurity? Indian Pediatr. 2016;53:80-4.

8. Vinekar A, Dogra MR, Sangtam T, Narang A, Gupta A. Retinopathy of prematurity in Asian Indian babies weighing greater than 1250 grams at birth: ten year data from a tertiary care center in a developing country. Indian J Ophthalmol. 2007;55:331-6.

9. Fierson WM. American Academy of Pediatrics Section on Ophthalmology, American Academy of Ophthalmology, American Association for Pediatric Ophthalmology and Strabismus, American Association of Certified Orthoptists. Screening examination of premature infants for retinopathy of prematurity. Pediatrics. 2013;131:189-95.

10. National Neonatology Forum. Clinical practice guidelines: Retinopathy of prematurity. National Neonatology Forum. 2010. https://www.ontop-in.org/ontop-pen/Week-12-13/ROP\%20NNF $\% 20$ Guidelines\%20.pdf.

11. Rashtriyabalswasthyakaryakram, Ministry of Health \& Family Welfare, Government of India. Guidelines for Universal Eye Screening in Newborns including Retinopathy of Prematurity. 2017. http://www.nhm.gov.in/images/pdf/programmes/RBSK/Resource_ Documents/Revised_ROP_Guidelines-Web_Optimized.pdf.

12. Expert group on prevention and treatment of oxygen and retinopathy in preterm infants. Guidelines for prevention and treatment of oxygen and retinopathy in preterm infants. Chin J Pediatr. 2007; 45: 672-3.

13. Xu Y, Zhou X, Zhang Q, Ji X, Zhang Q, Zhu J, et al. Screening for retinopathy of prematurity in China: a neonatal units-based prospective study. Investig Ophthalmol Vis Sci. 2013;54:8229-36.

14. Bas AY, Demirel N, Koc E, UlubasIsik D, Hirfanoglu IM, Tunc $\mathrm{T}$, et al. Incidence, risk factors and severity of retinopathy of prematurity in Turkey (TR-ROP study): a prospective, multicentre study in 69 neonatal intensive care units. Br J Ophthalmol. 2018. https://doi.org/10.1136/bjophthalmol-2017-311789.

15. Trinavarat A, Atchaneeyasakul L, Udompunturak S. Applicability of American and British criteria for screening of the retinopathy of prematurity in Thailand. Jpn J Ophthalmol. 2004;48:50-3.

16. Hwang JH, Lee EH, Kim EA-R. Retinopathy of prematurity among very-low-birth-weight infants in Korea: incidence, treatment, and risk factors. J Korean Med Sci. 2015;30:88-94.
17. Chen YH, Lien RI, Tsai S, Chang CJ, Lai CC, Chao AN, et al. Natural history of retinopathy of prematurity: two-year outcomes of a prospective study. Retina. 2015;35:141-8.

18. Shah VA, Yeo CL, Ling YLF, Ho LY. Incidence, risk factors of retinopathy of prematurity among very low birth weight infants in Singapore. Ann Acad Med Singap. 2005;34:169-78.

19. Aikawa H, Noro M. Low incidence of sight-threatening retinopathy of prematurity in infants born before 28 weeks gestation at a neonatal intensive care unit in Japan. Tohoku J Exp Med. 2013;230:185-90.

20. Vinekar A, Gilbert C, Dogra M, Kurian M, Shainesh G, Shetty B, et al. The KIDROP model of combining strategies for providing retinopathy of prematurity screening in underserved areas in India using wide-field imaging, tele-medicine, non-physician graders and smart phone reporting. Indian J Ophthalmol. 2014;62:41-9.

21. Vinekar A, Mangalesh S, Jayadev C, Gilbert C, Dogra M, Shetty B. Impact of expansion of telemedicine screening for retinopathy of prematurity in India. Indian J Ophthalmol. 2017;65:390-5.

22. Vinekar A, Azad R, Dogra MR, Narendran V, Jalali S, Bende P. The Indian retinopathy of prematurity society: a baby step towards tackling the retinopathy of prematurity epidemic in India. Ann Eye Sci. 2017;2:27.

23. Chen SD, Sundaram V, Wilkinson A, Patel CK. Variation in anaesthesia for the laser treatment of retinopathy of prematuritya survey of ophthalmologists in the UK. Eye. 2007;21:1033-6.

24. Axer-Siegel R, Snir M, Ron Y, Friling R, Sirota L, Weinberger D. Intravitrealbevacizumab as supplemental treatment or monotherapy for severe retinopathy of prematurity. Retina. 2011;31:1239-47.

25. Jiang J-bo, Strauss R, Luo X-qiong, Nie C, Wang YL, Zhang JW, et al. Anaesthesia modalities during laser photocoagulation for retinopathy of prematurity: a retrospective, longitudinal study. BMJ Open. 2017;7:e013344.

26. Şekeroğlu MA, Hekimoğlu E, Özcan B, Baş AY, Demirel N, Karakaya J. Bedside diode laser photocoagulation under remifentanil analgesia for retinopathy of prematurity: early structural outcomes. Turk J Ophthalmol. 2016;46:209-14.

27. Sato Y, Oshiro M, Takemoto K, Hosono H, Saito A, Kondo T, et al. Multicenter observational study comparing sedation/ analgesia protocols for laser photocoagulation treatment of retinopathy of prematurity. J Perinatol. 2015;35:965-9.

28. Dogra MR, Vinekar A, Viswanathan K, Sangtam T, Das P, Gupta A, et al. Laser treatment for retinopathy of prematurity through the incubator wall. Ophthalmic Surg Lasers Imaging. 2008;39: $350-2$.

29. Ells AL, Gole GA, Hildebrand PL, Ingram A, Wilson CM, Williams RG. Posterior to the ridge laser treatment for severe stage 3 retinopathy of prematurity. Eye. 2013;27:525-30.

30. Katoch D, Sanghi G, Dogra MR, Beke N, Gupta A. Structural sequelae and refractive outcome 1 year after laser treatment for type 1 prethreshold retinopathy of prematurity in Asian Indian eyes. Indian J Ophthalmol. 2011;59:423-6.

31. Sanghi G, Dogra MR, Katoch D, Gupta A. Aggressive posterior retinopathy of prematurity: risk factors for retinal detachment despite confluent laser photocoagulation. Am J Ophthalmol. 2013; 155:159-64.

32. Sanghi G, Dogra MR, Katoch D, Gupta A. Aggressive posterior retinopathy of prematurity in infants $\geq 1500 \mathrm{~g}$ birth weight. Indian J Ophthalmol. 2014;62:254-7.

33. Mintz-Hittner HA, Kennedy KA, Chuang AZ. BEAT-ROP Cooperative group. Efficacy of intravitreal bevacizumab for stage 3+ retinopathy of prematurity. N Engl J Med. 2011;364:603-15.

34. Lorenz B, Stieger K, Jager M, Mais C, Stieger S, AndrassiDarida M. Retinal vascular development with $0.312 \mathrm{mg}$ intravitreal bevacizumab to treat severe posterior retinopathy of prematurity: A Longitudinal Fluorescein Angiographic Study. Retina. 2017;37:97-111. 
35. Ahmed AE, Channa R, Durrani J, Ali A, Ahmad K. Early experience with intravitreal bevacizumab combined with laser treatment for retinopathy of prematurity. Middle East Afr J Ophthalmol. 2010;17:264-7.

36. Xu Y, Kang X, Zhang Q, Huang Q, Lv J, Zhao P. Combination of intravitreal injection of ranibizumab and photocoagulation for the treatment of aggressive posterior retinopathy of prematurity with vitreous hemorrhage. J ophthalmol. 2016;2016:e5029278.

37. Shah PK, Narendran V, Tawansy KA, Raghuram A, Narendran K. Intravitrealbevacizumab (Avastin) for post laser anterior segment ischemia in aggressive posterior retinopathy of prematurity. Indian J Ophthalmol. 2007;55:75-6.

38. Wu WC, Yeh PT, Chen SN, Yang CM, Lai CC, Kuo HK. Effects and complications of bevacizumab use in patients with retinopathy of prematurity: a multicenter study in taiwan. Ophthalmology. 2011;118:176-83.

39. Jalali S, Balakrishnan D, Zeynalova Z, Padhi TR, Rani PK. Serious adverse events and visual outcomes of rescue therapy using adjunct bevacizumab to laser and surgery for retinopathy of prematurity. The Indian Twin Cities Retinopathy of Prematurity Screening database Report number 5. Arch Dis Child Fetal Neonatal Ed. 2013;98:327-33.

40. Yonekawa Y, Wu WC, Nitulescu CE, Chan RP, Thanos A, Thomas BJ, et al. Progressive retinal detachment in infants with retinopathy of prematurity treated with intravitreal bevacizumab or ranibizumab. Retina. 2018;38:1079-83.

41. Wu WC, Lien R, Liao PJ, Wang NK, Chen YP, Chao AN, et al. Serum levels of vascular endothelial growth factor and related factors after intravitreousbevacizumab injection for retinopathy of prematurity. JAMA Ophthalmol. 2015;133:391-7.

42. Huang CY, Lien R, Wang NK, Chao AN, Chen KJ, Chen TL, et al. Changes in systemic vascular endothelial growth factor levels after intravitreal injection of aflibercept in infants with retinopathy of prematurity. Graefes Arch Clin Exp Ophthalmol. 2018;256:479-87.

43. Morin J, Luu TM, Superstein R, Ospina LH, Lefebvre F, Simard MN, et al. Neurodevelopmental outcomes following bevacizumab injections for retinopathy of prematurity. Pediatrics. 2016;137: e20153218.

44. Wu WC, Shih CP, Lien R, Wang NK, Chen YP, Chao AN, et al. Serum vascular endothelial growth factor after bevacizumab or ranibizumab treatment for retinopathy of prematurity. Retina. 2017;37:694-701.

45. Wu WC, Kuo HK, Yeh PT, Yang CM, Lai CC, Chen SN. An updated study of the use of bevacizumab in the treatment of patients with prethreshold retinopathy of prematurity in taiwan. Am J Ophthalmol. 2013;155:150-8.

46. Chuang YC, Yang CM. Scleral buckling for stage 4 retinopathy of prematurity. Ophthalmic Surg Lasers Imaging Retin. 2000;31:374-9.

47. Nishina S, Yokoi T, Yokoi T, Kobayashi Y, Hiraoka M, Azuma $\mathrm{N}$. Effect of early vitreous surgery for aggressive posterior retinopathy of prematurity detected by fundus fluorescein angiography. Ophthalmology. 2009;116:2442-7.

48. Gonzales CR, Boshra J, Schwartz SD. 25-Gauge pars plicata vitrectomy for stage 4 and 5 retinopathy of prematurity. Retina. 2006;26:42-6.

49. Gadkari SS, Deshpande M. Variation in the vitreoretinal configuration of Stage 4 retinopathy of prematurity in photocoagulated and treatment naive eyes undergoing vitrectomy. Indian J Ophthalmol. 2017;65:846-52.

50. Bhende P, Gopal L, Sharma T, Verma A, Biswas RK. Functional and anatomical outcomes after primary lens-sparing pars plana vitrectomy for stage 4 retinopathy of prematurity. Indian J Ophthalmol. 2009;57:267-71.

51. Xu Y, Zhang Q, Kang X, Zhu Y, Li J, Chen Y, et al. Early vitreoretinal surgery on vascularly active stage 4 retinopathy of prematurity through the preoperative intravitreal bevacizumab injection. Acta ophthalmol. 2013;91:304-10.

52. Azuma N, Ishikawa K, Hama Y, Hiraoka M, Suzuki Y, Nishina S. Early vitreous surgery for aggressive posterior retinopathy of prematurity. Am J Ophthalmol. 2006;142:636-43.

53. Gopal L, Sharma T, Shanmugam M, Badrinath SS, Sharma A, Agraharam SG, et al. Surgery for stage 5 retinopathy of prematurity: the learning curve and evolving technique. Indian $\mathbf{J}$ Ophthalmol. 2000;48:101-6.

54. Choi J, Kim JH, Kim SJ, Yu YS. Long-term results of lenssparing vitrectomy for stages $4 \mathrm{~B}$ and 5 retinopathy of prematurity. Korean J Ophthalmol. 2011;25:305-10.

55. Kondo H, Arita N, Osata M, Hayashi H, Oshima K, Uchio E. Late recurrence of retinal detachment following successful vitreous surgery for stages $4 \mathrm{~B}$ and 5 retinopathy of prematurity. Am J Ophthalmol. 2009;147:661-6.

56. Wu WC, Drenser KA, Lai M, Capone A, Trese MT. Plasmin enzyme-assisted vitrectomy for primary and reoperated eyes with stage 5 retinopathy of prematurity. Retina. 2008;28:75-80.

57. Rathi S, Jalali S, Patnaik S, et al. Abnormal complement activation and inflammation in the pathogenesis of retinopathy of prematurity. Front Immunol. 2017;8:1868.

58. Kondo H, Kusaka S, Yoshinaga A, Uchio E, Tawara A, Tahira T. Genetic variants of FZD4 and LRP5 genes in patients with advanced retinopathy of prematurity. Mol Vis. 2013;19:476-85.

59. CDC. Developing an effective evaluation report. CDC; 2013. https://www.cdc.gov/eval/materialsDevelopingAnEffectiveEvalua tionReport_TAG508.pdf.

60. Vinekar A, Dogra MR, Jayadev C. Evaluation of a new, low-cost, portable, wide-field digital retinal camera, "Neo" for screening infants or retinopathy of prematurity - a prospective, multi-center, validation report in Asian Indian infants. Investig Ophthalmol Vis Sci. 2016; 57. http://iovs.arvojournals.org/article.aspx?articleid= 25557805\&resultClick $=1 \# 139816184$.

61. WISE-ROP program. http://www.digihealthplatform.com/project/ wise-rop-program/.

62. Gilbert C, Wormald R, Fielder A, Deorari A, Zepeda-Romero LC, Quinn G, et al. Potential for a paradigm change in the detection of retinopathy of prematurity requiring treatment. Arch Dis Child Fetal Neonatal Ed. 2016;101:F6-9.

63. Wilkinson AR, Haines L, Head K, Fielder AR. Guideline Development Group of the Royal College of Paediatrics and Child Health, Royal College of Ophthalmologists et al. UK retinopathy of prematurity guideline. Eye. 2009;23:2137-9.

64. Al Amro SA, Al Aql F, Al Hajar S, Al Dhibi H, Al Nemri A, Mousa A, et al. Practical guidelines for screening and treatment of retinopathy of prematurity in Saudi Arabia. Saudi J Ophthalmol. 2018;32:222-6.

65. Sanghi G, Dogra MR, Vinekar A, Gupta A. Frequency-doubled $\mathrm{Nd}$ :YAG (532 $\mathrm{nm}$ green) versus diode laser $(810 \mathrm{~nm})$ in treatment of retinopathy of prematurity. Br J Ophthalmol. 2010;94:1264-5.

66. Jalali S, Azad R, Trehan HS, Dogra MR, Gopal L, Narendran V. Technical aspects of laser treatment for acute retinopathy of prematurity under topical anesthesia. Indian $\mathrm{J}$ Ophthalmol. 2010;58:509-15.

67. Uparkar M, Sen P, Rawal A, Agarwal S, Khan B, Gopal L. Laser photocoagulation $(810 \mathrm{~nm}$ diode) for threshold retinopathy of prematurity: a prospective randomized pilot study of treatment to ridge and avascular retina versus avascular retina alone. Int Ophthalmol. 2011;31:3-8.

68. Parvaresh MM, Falavarjani KG, Modarres M, Nazari H, Saiepour N. Transscleral diode laser photocoagulation for type 1 prethreshold retinopathy of prematurity. J Ophthalmic Vis Res. 2013;8:298-302.

69. Vinekar A, Jayadev C, Mangalesh S, Kumar AK, Bauer N, Capone JrA, et al. Comparing the outcome of single versus 
multiple session laser photoablation of flat neovascularization in zone 1 aggressive posterior retinopathy of prematurity: a prospective randomized study. Retina. 2015;35:2130-6.

70. Kusaka S, Shima C, Wada K, Arahori H, Shimojyo H, Sato T, et al. Efficacy of intravitreal injection of bevacizumab for severe retinopathy of prematurity: a pilot study. $\mathrm{Br} \mathrm{J}$ Ophthalmol. 2008;92:1450-5.

71. Yetik H, Gunay M, Sirop S, Salihoglu Z. Intravitreal bevacizumab monotherapy for type-1 prethreshold, threshold, and aggressive posterior retinopathy of prematurity -27 month follow-up results from Turkey. Graefes Arch Clin Exp Ophthalmol. 2015;253:1677-83.

72. Huang Q, Zhang Q, Fei P, Xu Y, Lyu J, Ji X, et al. Ranibizumab injection as primary treatment in patients with retinopathy of prematurity: anatomic outcomes and influencing factors. Ophthalmology. 2017;124:1156-64.

73. Yu YS, Kim SJ, Kim SY, Choung HK, Park GH, Heo JW. Lenssparing vitrectomy for stage 4 and stage 5 retinopathy of prematurity. Korean J Ophthalmol. 2006;20:113-7.

74. Wu WC, Lai CC, Lin RI, Wang NK, Chao AN, Chen KJ, et al. Modified 23-gauge vitrectomy system for stage 4 retinopathy of prematurity. Arch Ophthalmol. 2011;129:1326-31.

75. Gadkari S, Kamdar R, Kulkarni S, Kakade N, Taras S, Deshpande M. Vitreoretinal surgery for advanced retinopathy of prematurity: presentation and outcomes from a developing country. Can J Ophthalmol. 2015;50:54-60.

76. Shah PK, Prabhu V, Narendran V. Outcomes of transconjuctival sutureless 27 -gauge vitrectomy for stage 4 retinopathy of prematurity. World J Clin Pediatr. 2018;7:62-6.
77. Shah PK, Narendran V, Kalpana N, Tawansy KA. Anatomic and visual outcomes of stage 4 \& 5 ROP. Eye. 2009;23:176-80.

78. Karacorlu M, Hocaoglu M, Sayman Muslubas I, Arf S. Long-term functional results following vitrectomy for advanced retinopathy of prematurity. Br J Ophthalmol. 2017;101:730-4.

79. Kono T, Oshima K, Fuchino Y. Surgical results and visual outcomes of vitreous surgery for advanced stages of retinopathy of prematurity. Jpn J Ophthalmol. 2000;44:661-7.

80. Cusick M, Charles MK, Agron E, Sangiovanni JP, Ferris FL 3rd, Charles S. Anatomical and visual results of vitreoretinal surgery for stage 5 retinopathy of prematurity. Retina. 2006;26:729-35.

81. Axer-Siegel R, Maharshak I, Snir M, Friling R, Ehrlich R, Sherf I, et al. Diode laser treatment of retinopathy of prematurity: anatomical and refractive outcomes. Retina. 2008;28:839-46.

82. Agarkar S, Desai R, Singh S, Jaisankar D, Bhende P, Raman R. Influence of laser versus lens-sparing vitrectomy on myopia in children with retinopathy of prematurity. Indian $\mathrm{J}$ Ophthalmol. 2017;65:841-5.

83. Chen YH, Chen SN, Lien RI, Shih CP, Chao AN, Chen KJ, et al. Refractive errors after the use of bevacizumab for the treatment of retinopathy of prematurity: 2-year outcomes. Eye. 2014;28:1080-7.

84. Yang CS, Wang AG, Sung CS, Hsu WM, Lee FL, Lee SM. Longterm visual outcomes of laser-treated threshold retinopathy of prematurity: a study of refractive status at 7 years. Eye. 2010;24:14-20.

85. Shah PK, Ramakrishnan M, Sadat B, Bachu S, Narendran V, Kalpana N. Long term refractive and structural outcome following laser treatment for zone 1 aggressive posterior retinopathy of prematurity. Oman J Ophthalmol. 2014;7:116-9. 